\title{
Impact of graduated driver licensing restrictions on crashes involving young drivers in $\mathrm{New}$ Zealand
}

\author{
D J Begg, S Stephenson, J Alsop, J Langley
}

\begin{abstract}
Objective-To determine the impact on young driver crashes of the three main driving restrictions in the New Zealand graduated driver licensing (GDL) system: night-time curfew, no carrying of young passengers, and a blood alcohol limit of 30 $\mathrm{mg} / 100 \mathrm{ml}$.

Method-The database for this study was created by linking police crash reports to hospital inpatient records (1980-95). Multivariate logistic regression was used to compare car crashes involving a young driver licensed before GDL $(n=2252)$ with those who held a restricted graduated licence $(n=980)$ and with those who held a full graduated licence $(n=1273)$, for each of the main driving restrictions.

Results-Compared with the pre-GDL group, the restricted licence drivers had fewer crashes at night $(p=0.003)$, fewer involving passengers of all ages $(p=0.018)$, and fewer where alcohol was suspected $(p=0.034)$, but not fewer involving young casualties $(p=0.980)$. Compared with the pre-GDL drivers, those with the full graduated licence had fewer night crashes $(p=0.042)$ but did not differ significantly for any of the other factors examined. Conclusion-These results suggest that some of the GDL restrictions, especially the night-time curfew, have contributed to a reduction in serious crashes involving young drivers.

(Injury Prevention 2001;7:292-296)
\end{abstract}

Keywords: young drivers; graduated driver licensing; driving restrictions; motor vehicle crashes

Like all motorised countries, ${ }^{1} \mathrm{New}$ Zealand has a problem with young drivers. Over recent years, the most important policy initiative aimed at addressing this problem in New Zealand was the introduction of a graduated driver licensing (GDL) system. Although the idea of graduated licensing has been around since the 1970 s, $^{2}$ the first comprehensive, multistage system was introduced in New Zealand in 1987. ${ }^{1}$ Since then the popularity of this measure has increased, and in the United States in 1999 it was described as "a major public health movement". ${ }^{1}$ A similar situation exists in Canada. ${ }^{3}$

The New Zealand system, as introduced in August 1987, remained essentially unchanged until 1999. (The changes made in 1999 do not apply to this study and will be discussed later.)
Before the introduction of the GDL system a full driver's licence could be applied for at age 15. Obtaining this licence involved passing a written and oral test, and a practical driving test, all of which could be achieved on the 15th birthday. The 1987 GDL system applied to all car drivers aged 15-24 years, and had three licensing stages: learner licence, restricted licence, and full licence. Acquiring a learner licence required passing a theory and an eyesight test. With this licence the young driver had to be accompanied by a supervisor (that is, a fully licensed driver at least 20 years old, who had held a full licence for two years) and the blood alcohol limit was $30 \mathrm{mg} / 100 \mathrm{ml}$ of blood (blood alcohol concentration (BAC) 0.03). The duration of the learner licence was six months, although this could be reduced to three months by passing an approved driving course. The restricted licence required passing a practical driving test and included a nighttime driving curfew (10 pm to $5 \mathrm{am}$ ) and a restriction on the carrying of passengers under 20 years of age (other than dependents or a spouse), unless accompanied by a supervisor. As with the learner licence, the BAC was 0.03 . The restricted licence was for 18 months, although this could be reduced to nine months by completing an approved course (for example, defensive driving course, or an advanced driving course). After completing the restricted licence stage, no further testing was required to obtain a full licence.

Evaluation studies have shown that the New Zealand GDL system has been associated with a substantial reduction in the number of traffic related injuries to young people. Although the GDL system applied to all 15-24 year olds, evaluations have targeted the 15-19 year olds, the main age affected by this licensing system. The first of these evaluations showed that immediately after the introduction of GDL, there was a large decrease in the number of young driver (15-19 year old) crashes, and also in the ratio of young driver crashes compared with crashes involving drivers aged 25 or older. ${ }^{4}$ Although this effect partially dissipated after two years, the GDL system was associated with an ongoing reduction of around $8 \%$ in the proportion of crashes involving young drivers. These findings were supported by the results from a second study where time series analyses compared trends in hospital admissions for car occupants before and after the introduction of GDL. ${ }^{5}$ These results showed a significant $23 \%$ reduction in the number of $15-19$ year olds hospitalized after the introduction of the GDL 
system. After taking into account other factors, such as trends in crash related injury in other age groups, trends in non-traffic injuries to 15-19 year olds, and unemployment, it was concluded that at least a $7 \%$ reduction in crash related injury among 15-19 year olds could be attributed to GDL.

These, however, were ecological studies and could not determine whether the reduction in injury was due to the specific conditions of the GDL system, or some other unaccounted for factor, such as decreased driving by young people. The latter was considered a likely explanation because immediately after GDL was introduced, there was evidence of a sharp decrease in the number of licensed drivers in the $15-19$ year age group. ${ }^{45}$ Since that initial decrease, however, the rate of young licensed drivers appears to have recovered to a level similar to that before GDL. ${ }^{6}$ At the same time, the number of crashes involving young drivers has continued to decrease resulting in a decrease in the fatality and hospital admission rate of licensed drivers. ${ }^{7-9}$ For example, the car crash fatality and hospital admission rate per 10000 licensed drivers for 15-19 year old drivers has decreased from approximately 37 in 1985 (pre-GDL) to 25 in 1990 and 20 in 1996. ${ }^{9-11}$ The GDL system, therefore, has been associated with an ongoing decrease in the number of crash related injuries to young people, but more importantly a decrease in the rate per number of licensed drivers.

As a "total package" GDL has reduced young driver crashes in New Zealand. However, it is important to assess the relative effectiveness of the various components of the system, to try and identify ways in which the system may be improved. The main purpose of the present study was to determine the extent to which each of the restrictions of the New Zealand GDL system may have contributed to the reduced crash rate. We hypothesised that if the restrictions had contributed to this decrease then, of the crashes that did occur, the proportion that (a) occurred at night (10 pm to $5 \mathrm{am}$ ), (b) involved young passengers, or (c) involved alcohol, would be lower for drivers licensed under the GDL system, compared with a young driver licensed under the old system. This would apply especially to the GDL system restricted licence drivers, who were those most directly affected by the restrictions. However, if the experience gained during the learner and restricted licence stages results in ongoing safety benefits, then this would also apply to drivers with a full graduated licence. The learner licence drivers, who must always be accompanied by a supervisor, are comparable to drivers before they obtained a licence under the old licensing system and are, therefore, not included in the analyses.

\section{Method}

For this study it was necessary to create a single database that contained information relevant to all the GDL system restrictions (night-time curfew, young passengers, alcohol) but was not biased with respect to the factors being investigated. The best source of crash data was the police traffic crash reports, but it was of concern that this database may be biased towards the factors being studied. For example, it is known that there is underreporting of crashes to the police, ${ }^{12-14}$ so if there were changes in the reporting rate of crashes that involved one or more of the driving restrictions, the results may be due to changes in reporting rates, rather than the actual restrictions.

For the present study this potential problem was overcome by matching police reports to the New Zealand Health Information Service (NZHIS) hospital inpatient file. ${ }^{15}$ The NZHIS maintains a record of all persons admitted to a public hospital for treatment of an injury including crash victims, and all injury discharges are E coded. ${ }^{16}$ The sole criterion for a record to be included on the hospital file is admission to hospital, which can be considered a proxy measure of injury severity. This should not be influenced by police reporting practices, or biased by whether a crash occurred at night, involved young passengers, or involved alcohol.

Following the procedure established by Alsop and Langley, ${ }^{14}$ individual records in the New Zealand police traffic crash report file for 1980-95 were matched to the records for the same individuals and crash events in the NZHISs' hospital inpatient file. On the hospital file traffic crash victims were identified by $\mathrm{E}$ codes 810-819 and motor vehicle occupants by using the fourth digit of the $\mathrm{E}$ code ( 0 for driver, 1 for passenger). ${ }^{17}$ The linked database, therefore, contained only records where a vehicle occupant had been admitted to hospital. Records were excluded where the licence status of the driver was undetermined or missing, or was recorded as unlicensed or disqualified. A summary of the licence status for all drivers with a linked record is given in table 1 . This shows that of the grand total of 6693 cases, $4505(67 \%)$ were included in the analyses. Of these, $2252(50 \%)$ were licensed pre-GDL, $1273(28 \%)$ had a full graduated licence, 980 $(22 \%)$ a restricted licence; $3435(76 \%)$ were male, and 1069 (24\%) female.

The main unit of analysis was a motor vehicle involved in a crash where the driver was 15-19 years, inclusive. The traffic crash reports were used to identify the night-time $(10 \mathrm{pm}$ to $5 \mathrm{am})$ crashes and the presence of passengers. The involvement of passengers less than 20 years of age was limited to the crashes involving an injured passenger (that is, young casualty).

Table 1 Licence status for all drivers identified in the linked dataset, by gender; values are frequency (\%)

\begin{tabular}{lccc}
\hline Licence type & Males & Females & \multicolumn{1}{l}{ Total } \\
\hline Drivers included in analyses & $1814(53)$ & $438(41)$ & $2252(50)$ \\
$\quad$ Pre-GDL & $949(28)$ & $324(30)$ & $1273(28)$ \\
Full graduated licence & $672(19)$ & $307(29)$ & $980(22)$ \\
Restricted licence & $3435(100)$ & $1069(100)$ & $4505(100)$ \\
Subtotal & 273 & 126 & \\
Drivers excluded from analyses & & 399 \\
$\quad$ Learner licence & 273 & 446 & 1789 \\
Licence status unknown & 1342 & 572 & 2188 \\
Subtotal & 1615 & 1641 & 6693 \\
Grand total & 5050 & & \\
\hline
\end{tabular}

${ }^{\star}$ Gender missing for one case that is included in the total. 
Table 2 The number and proportion of young driver crashes that occurred at night, involved passengers (any age), involved young casualties, and where alcohol was suspected, by driver licence status; values are frequency (\%)

\begin{tabular}{lrrr}
\hline & \multicolumn{1}{l}{ No } & \multicolumn{1}{l}{ Yes } & Total \\
\hline Night-time crashes & & & \\
$\quad$ Pre-GDL & $1416(63)$ & $836(37)$ & 2252 \\
Restricted licence & $713(73)$ & $267(27)$ & 980 \\
$\quad$ Full graduated licence & $875(69)$ & $398(31)$ & 1273 \\
All passengers & & & \\
$\quad$ Pre-GDL & $856(38)$ & $1396(62)$ & 2252 \\
$\quad$ Restricted licence & $422(42)$ & $568(58)$ & 980 \\
Full graduated licence & $484(38)$ & $789(62)$ & 1273 \\
Young casualties & & & \\
$\quad$ Pre-GDL & $302(29)$ & $738(71)$ & 1040 \\
Restricted licence & $115(26)$ & $327(74)$ & 442 \\
Full graduated licence & $149(26)$ & $423(74)$ & 572 \\
Alcohol suspected & & & \\
$\quad$ Pre-GDL & $1617(72)$ & $635(28)$ & 2252 \\
Restricted licence & $779(79)$ & $201(21)$ & 980 \\
Full graduated licence & $1003(79)$ & $270(21)$ & 1273 \\
\hline
\end{tabular}

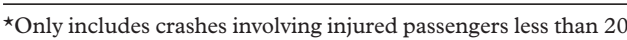
years old.

The involvement of alcohol was assessed by the police officer who recorded "whether the driver was thought to have been drinking". There is some evidence that this is a reasonably accurate indicator if alcohol is present. ${ }^{18}$

For the statistical analyses multivariate logistic regression were used to compare the pre-GDL group with the restricted licence group, and the pre-GDL group with the full GDL group. Separate regression models were fitted where each of the four driving restrictions were the response variables.

(1) Night-time curfew crashes.

(2) Crashes involving passengers of all ages.

(3) Crashes involving young casualties.

(4) Crashes where alcohol was suspected.

To control for potential confounding effects, factors known to be strongly associated with

Table 3 An example of the full logistic regression model used to compare the proportion of crashes where the response variable was one of the driving restrictions (night-time curfew in this example) and the main explanatory variable was type of licence (in this example pre-GDL drivers were compared with restricted licence drivers)

\begin{tabular}{llcccccc}
\hline Estimates & $d f$ & Estimate & $S E$ & $\chi^{2}$ & $\begin{array}{l}p \text { Value } \\
>\chi^{2}\end{array}$ & $\begin{array}{l}\text { Odds } \\
\text { ratio }\end{array}$ & $\begin{array}{l}\text { 95\% confidence } \\
\text { interval }\end{array}$ \\
\hline $\begin{array}{l}\text { Intercept } \\
\text { Licence type }\end{array}$ & 1 & 1.809 & 1.504 & 1.45 & 0.229 & & \\
$\quad \begin{array}{l}\text { Pre-GDL: restricted } \\
\text { Driver age (years) }\end{array}$ & 1 & -0.42 & 0.14 & 9.13 & 0.003 & 0.66 & 0.50 to 0.86 \\
$\quad 19: 15$ & 1 & 0.786 & 0.120 & 15.5 & $<0.0001$ & 2.20 & 1.50 to 3.29 \\
$\quad 19: 16$ & 1 & 0.606 & 0.124 & 23.7 & $<0.0001$ & 1.83 & 1.44 to 2.34 \\
$\quad 19: 17$ & 1 & 0.221 & 0.106 & 4.34 & 0.037 & 1.25 & 1.01 to 1.54 \\
$\quad 19: 18$ & 1 & 0.041 & 0.098 & 0.18 & 0.676 & 1.04 & 0.86 to 1.26 \\
$\begin{array}{l}\text { Gender } \\
\quad \text { Female: male }\end{array}$ & 1 & 0.463 & 0.095 & 23.55 & $<0.0001$ & 1.59 & 1.32 to 1.92 \\
$\quad$ Year of crash & 1 & -0.013 & 0.016 & 0.65 & 0.422 & 0.99 & 0.96 to 1.02 \\
\hline
\end{tabular}

Table 4 The results from the regression models where the main explanatory variables pre-GDL $v$ restricted licence, and pre-GDL $v$ full graduated licence, and the response variables were each of the four driving restrictions

\begin{tabular}{|c|c|c|c|}
\hline Driving restriction (response variable) & Odds ratio * & $\begin{array}{l}95 \% \text { confidence } \\
\text { interval }\end{array}$ & $p$ Value \\
\hline \multicolumn{4}{|l|}{ Pre-GDL $v$ restricted licence } \\
\hline Night-time curfew (10pm to $5 \mathrm{am})$ & 0.66 & 0.50 to 0.86 & 0.003 \\
\hline Passengers (all ages) & 0.73 & 0.56 to 0.95 & 0.018 \\
\hline Young casualties & 1.01 & 0.64 to 1.58 & 0.980 \\
\hline Alcohol suspected & 0.72 & 0.54 to 0.98 & 0.034 \\
\hline \multicolumn{4}{|l|}{ Pre-GDL $v$ full graduated licence } \\
\hline Night-time curfew (10pm to $5 \mathrm{am})$ & 0.77 & 0.60 to 0.99 & 0.042 \\
\hline Passengers (all ages) & 0.98 & 0.77 to 1.26 & 0.887 \\
\hline Young casualties & 0.96 & 0.64 to 1.44 & 0.838 \\
\hline Alcohol suspected & 0.85 & 0.65 to 1.13 & 0.260 \\
\hline
\end{tabular}

${ }^{\star}$ Adjusted for driver age and gender, and year of crash. young driver crashes were included as covariates in the models. These covariates were gender and age. To control for linear trends that may have arisen as the result of other interventions over the period covered by this study, the year in which the crash occurred was included the model.

\section{Results}

A summary of the number and percentage of crashes that involved each of the driving restrictions are given, by driver licence status, in table 2. For the night-time, all passenger, and alcohol suspected crashes, all of the linked crashes were used, but the young casualty comparisons were based only on crashes where there was an injured passenger, hence the reduced totals.

Table 3 provides an example of the full logistic regression model that was used for all of the eight regression models. In this example (table 3 ) the response (or dependent) variable was a night-time crash (yes/no) and the main explanatory (or independent) variable was driver licence status, and in this example the preGDL licence group, which was classified as the reference group, was compared with the restricted licence group. The results show that, compared with the pre-GDL drivers, a significantly smaller proportion of the crashes involving a restricted licence driver occurred at night (odds ratio $0.66,95 \%$ confidence interval 0.50 to $0.86, \mathrm{p}=0.003$ ).

Four similar, separate logistic regression models were fitted using the same explanatory variables as were used in the example given in table 3. For these four models the main explanatory variable was the type of licence held by the driver (pre-GDL drivers were compared with the restricted licence drivers) and the four (yes/no) response variables were:

(1) Involvement in a crash during the nighttime curfew.

(2) Involvement in a crash with passengers (all ages).

(3) Involvement in a crash with a young casualty.

(4) Involvement in a crash where alcohol was suspected.

The results for the main explanatory variable, for each of the four response variables, are given in the upper section of table 4. This shows that, compared with drivers licensed pre-GDL, restricted licence drivers had a significantly smaller proportion of crashes that occurred during the night-time curfew $(\mathrm{p}=0.003)$, a significantly smaller proportion of crashes that involved passengers of all ages $(\mathrm{p}=0.018)$, and also a significantly smaller proportion of crashes where alcohol was suspected $(p=0.034)$, but for crashes involving an injured passenger, there was no significant difference $(\mathrm{p}=0.980)$.

The next stage of the analysis compared the crashes that involved a pre-GDL driver with those that involved a full graduated licensed driver. To do this four further models were fitted using the same four driving restriction response variables as were used in the previous 
models. The explanatory variables were also the same as used previously, except that for licence type those with a full graduated licence were compared with the pre-GDL group. The results for the main explanatory variable, pre-GDL versus full graduated licence, are given in the lower section of table 4 and show that those with a full graduated licence had a smaller proportion of crashes at night $(p=0.042)$ but there were no significant differences for any of the other restrictions.

\section{Discussion}

Earlier research has shown that, following the introduction of GDL in 1987, there had been a significant reduction in the number of young people seriously injured in traffic crashes, ${ }^{5}$ in the ratio of crashes involving a young driver compared to older drivers, ${ }^{4}$ and also in the rate of crashes per number of licensed drivers. ${ }^{69}$ The results from the present study show that, of the crashes that occurred between 1980 and 1995, those that involved a driver with a restricted licence were less likely to have occurred at night, less likely to have involved passengers, and less likely to have been suspected of involving alcohol, compared with crashes involving a driver licensed under the old system. This suggests that the GDL restrictions, and in particular the night-time driving curfew, have made a positive contribution to the reduction in young driver crashes that has occurred since the GDL system was introduced in 1987.

A full evaluation of the restriction on the carrying of passengers was not possible because data on passenger age was only available for those who had been injured. The results showed that among this group the restricted licence driver was just as likely to have young passengers as the pre-GDL driver. Although this study was not directly concerned with addressing issues of compliance with the driving restrictions, results such as this draw attention to the findings of previous research that have highlighted some of the problems of compliance, ${ }^{19} 20$ and especially breaches of the restriction on the carrying of young passengers.

Supporting the findings from other researchers, ${ }^{21-23}$ the night-time curfew appears to have contributed to a reduction in nighttime crashes. Because this was associated with a reduction in the actual number of crashes, we are confident that this result was not due to an increase in daytime crashes, but was either due to less or safer driving at night by young, restricted licensed drivers. It was also interesting to find that the drivers with a full graduated licence also had a lower proportion of crashes at night than the pre-GDL drivers, even though the night-time driving restriction no longer applied to them.

There are several possible explanations. It may have been that, compared to the pre-GDL drivers, those drivers with a full graduated license were safer drivers at night, they may have driven less at night, they may have been less likely to drive for no real purpose, or they may have been less likely to drink and drive.

\section{Key points}

- Evidence shows that graduated driver licensing has been an effective way of reducing traffic crash related injury among young people.

- A night-time driving curfew is an important component of a graduated licensing system.

- A restriction on the carrying of young passengers may help to reduce traffic related injury.

- There is some evidence of ongoing safety benefits from graduated licensing.

Irrespective of the reason, it is encouraging that the night-time curfew has helped reduce young driver crashes.

The results of this study also showed that the young restricted licence drivers compared with pre-GDL drivers had a reduced proportion of crashes where alcohol was suspected. There were, however, a number of factors other than the GDL system, that may have contributed to this result. In 1992 the $30 \mathrm{mg}$ per $100 \mathrm{ml}$ of blood alcohol limit was extended to include all young drivers under 20 years, irrespective of the type of licence they held. This would have had direct impact on the last few years of the present study, and hence the results presented here. In addition, a range of other strategies such as compulsory breath testing, booze buses, drink-drive blitzes, and media campaigns, have targeted drinking and driving in the whole driving population. These strategies should have had some effect on the behaviour of young drivers, making it is impossible to disentangle the effect of the GDL system alcohol restriction.

In May 1999, some changes were made to the New Zealand GDL system. Among these was a penalty regime comprising monetary fines and demerit points for violations. Breaches of a condition of either the learner or restricted licence incurs 25 demerit points and a $\$ 400$ (NZD) fine. If 100 demerit points are accumulated within a two year period, the licence is suspended for three months. Other changes to the GDL system in 1999 made it apply to all new drivers (was 15-24 year olds only), the time discount (that is, time reduction) associated with a learner licence was discontinued, the age limit for the supervisor removed, and the learner licence driver must display "L" plates. At the restricted licence stage, the time can be reduced from 18 to 12 months (six to three months for drivers over 25 years) by taking an approved driver education course. Also, to obtain a full licence the new driver must pass a practical test, which is designed to confirm basic driving skills and the ability to detect and respond to hazards in built-up areas and in higher speed zones. $^{24}$ The effect that these changes have on the effectiveness of the GDL system remains for the future. 


\section{Implications for prevention}

The New Zealand experience suggests that GDL has been an effective way of helping to reduce traffic crashes among young drivers. The results from this study indicate that driving restrictions, such as a night-time curfew, have directly contributed to this reduction, and should be an essential component of any GDL system. There was also some evidence that the passenger and alcohol restrictions may have contributed to the crash reduction, suggesting that these restrictions should also be given serious consideration by any jurisdiction developing a GDL system.

This research was funded by a grant from the Health Research Council of New Zealand (HRC). The Injury Prevention Council of New Zealand (HRC). The Injury Prevention
Research Unit is funded by the HRC and the Accident Research Unit is funded by the HRC and the Accident McLaren of the Land Transport Safety Authority, Wellington, for her comments on an earlier draft of this paper.

1 Williams A. Graduated licensing comes to the United States. Inj Prev 1999;5:133-5.

2 Waller P. The changing task of driver licensing. Future role of driver licensing in highway safety. Washington, DC: Transportation Research Board, 1974 .

3 Mayhew D. Safety of young drivers. Brisbane, Australia: National Conference on Injury Prevention and Control. 1999.

4 Frith W, Perkins W. The New Zealand graduated drivers licensing system. Wellington: New Zealand Road Traffic Safety Seminar, 1992

5 Langley J, Wagenaar A, Begg D. An evaluation of the New Zealand graduated driver licensing system. Accid Anal Prev 1996;28:139-46.

6 Land Transport Safety Authority. Motor accidents in New Zealand. Statistical statement calendar year 1995. Wellington: Land Transport Safety Authority, 1996.

7 Land Transport Safety Authority. Motor accidents in New Zealand. Statistical statement calendar year 1998. Wellington: Zealand. Statistical statement calendar year

8 New Zealand Health Information Service. Mortality and demographic data, 1996. Wellington: Ministry of Health, 1999.
9 New Zealand Health Information Service. Selected morbidity data for publicly funded hospitals 1995/96. Wellington: Ministry of Health, 1997.

10 1Land Transport Safety Authority. Motor accidents in New Zealand. Statistical statement calendar year 1996. Wellington: Land Transport Safety Authority, 1997.

11 Land Transport Safety Authority. Motor accidents in New Zealand. Statistical statement calendar year 1991. Wellington: Land Transport Safety Authority, 1992.

12 Land Transport Safety Authority. Motor accidents in New Zealand. Statistical statement calendar year 1997. Wellington: Land Transport Safety Authority, 1998.

13 Morrison P, Kjellstrom T. A comparison of hospital admission data and official government statistics of serious traffic accident injuries. N Z Med $\mathcal{f}$ 1987;100:517-20.

14 Alsop J, Langley J. Under-reporting of motor vehicle traffic crash victims in New Zealand. Accid Anal Prev 2001;33: 353-9.

15 New Zealand Health Information Service. Selected morbidity data for publicly funded hospitals 1996/97. Wellington: Ministry of Health, 1999.

16 Langley J. Experiences using New Zealand's hospital based surveillance system for injury prevention. Methods of Information in Medicine 1995;34:340-4.

17 World Health Organisation. International classification of diseases. Geneva: World Health Organisation, 1978.

18 Bailey JPM. The Waikato hospital road accident survey. Volume 2: Analysis and interpretation. Petone, Wellington: Department of Scientific and Industrial Research, 1984

19 Begg D, Langley J, Chalmers D, et al. The New Zealand graduated driver licensing system: teenagers attitudes towards and experiences with this car driver licensing system. Inj Prev 1995;1:177-81.

20 Harre N, Field J, Kirkwood B. Gender differences and areas of common concern in the driving behaviors and attitudes of adolescents. I Safety Res 1996;27:163-73.

21 Williams A, Preusser D. Night driving restrictions for youthful drivers: a literature review and commentary. $\mathcal{f}$ Public Health Policy 1997;18:334-45.

22 Preusser D, Williams A, Zador P, et al. The effect of curfew laws on motor vehicle crashes. Law and Policy 1984;6:11528

23 Preusser D, Zador P, Williams A. The effect of city curfew ordinances on teenage motor vehicle fatalities. Accid Anal Prev 1993;25:641-5.

24 Land Transport Safety Authority. The official New Zealand road code and licence guide for car drivers. Wellington: DLM Campaign Ltd, 1999. 